\title{
Polycarbonates from Cyclic Carbonates, Carbanions, and Dihalo Compounds
}

\author{
Gabriel RoKICKI and Piotr JEŻEWSKI \\ Faculty of Chemistry, Technical University (Politechnika), \\ 00-662 Warsaw, Poland
}

(Received February 2, 1988)

\begin{abstract}
A new route for the synthesis of polycarbonates in reactions of cyclic carbonates with potassium naphthalene and $\alpha, \omega$-dihalo compounds is presented. The mechanism of carbonate linkage formation involving 1,3-dioxolan-2-one ring opening is discussed. When oxiranes and $\mathrm{CO}_{2}$ were used instead of cyclic carbonates a product containing inbuilt polyether segments of various lengths was formed. It was found that the reaction of "living" polystyrene with cyclic carbonates and dihalo compounds given products containing polystyrene blocks in the polymer chains. The effects of various agents activating carbonate anions on yield and molecular weight of polycarbonates are examined.
\end{abstract}

KEY WORDS Cyclic Carbonate / Carbanions / $\alpha, \omega$-Dihalo Compounds / Polycarbonate / Polystyrene /

Carbon dioxide has been considered as a starting material for polymer synthesis for over a decade. ${ }^{1}$ The discovery of crown ethers ${ }^{2}$ as agents efficiently activating anions in low polar systems has contributed to more intensive research on polycondensation with the participation of $\mathrm{CO}_{2}$, mainly in the synthesis of polycarbonates. ${ }^{3-5}$

However, the products of such a reaction had relatively low molecular weights, which was due to the presence of residual protons originating from dilos or diphenols, not fully transformed into respective diolates or phenolates.

Since carbanions and anion-radicals react with oxiranes resulting in products with alcoholate terminal groups, ${ }^{5}$ such reactions, in a highly aprotic system, should enable the obtaining of entirely difunctional alcoholates. Carbon dioxide transforms them into more stable alkyl carbonate dianions, which in reaction $\alpha, \omega$-dihalo compounds lead to polycarbonates.
As is known, the reaction of carbanions and anion-radicals with esters ${ }^{6}$ or polyesters ${ }^{7}$ results in ketones or in products with new ester linkages.

Cyclic carbonates (which are products of $\mathrm{CO}_{2}$ addition to oxiranes) react with some nucleophilic agents in a specific way.

The 1,3-dioxolan-2-one group is subject to additive nucleophilic attack at the $\alpha$ carbon atom..$^{8,9}$

Hence, it seemed reasonable to examine the reactions of anion-radicals and carbanions with oxiranes and carbon dioxide as well as cyclic carbonates, and eventually use the products of such reactions (with alkyl-carbonate terminals) for further polycarbonate synthesis.

This paper is also concerned with the synthesis of polycarbonates containing polystyrene blocks using "living" polystyrene for reaction with cyclic carbonates and $\alpha, \omega$-dihalo compounds. 


\section{EXPERIMENTAL}

\section{Materials}

$\alpha, \alpha^{\prime}$-Dibromo- $p$-xylene was obtained from the reaction of $p$-xylene- $\alpha, \alpha^{\prime}$-diol with hydrogen bromide. $\alpha, \alpha^{\prime}$-Dichloro- $p$-xylene was obtained from the reaction of $p$-xylene with sulfuryl chloride carried out in the presence of benzoyl peroxide. 4,4'-Bis(bromomethyl)diphenyl ether was obtained from the reaction of diphenyl ether with paraformaldehyde in the presence of gaseous hydrogen bromide. The products were purified by crystallization from chloroform. ${ }^{10}$ Tetrahydrofuran (THF) was first dried over molecular sieves and then treated, under dry nitrogen, with a solution of sodium naphthalene in THF until a permanent green color characteristic of the complex remained, indicating complete drying. The solvent was subsequently distilled. Styrene and propylene oxide were purified by distillation from powdered calcium hydride.

Ethylene and propylene carbonate (Merck) were purified by vacuum distillation.

Polyglyme 300 was obtained from the re- action of polyethylene glycol 300 disodium salt with methyl bromide. TEBA (triethylbenzylammonium chloride) and BPP ( $n$ butyltriphenylphosphonium bromide) were obtained by known methods. 18-Crown-6 ether $(1,4,7,10,13,16$-hexaoxacyclooctadecane) (Merck) was used without further purification.

\section{Synthetic Method}

Synthesis of Polycarbonate from Potassium Naphthalene, Propylene Oxide, $\mathrm{CO}_{2}$, and $\alpha, \alpha^{\prime}-$ Dibromo-p-xylene. The synthesis of polycarbonate was carried out in a reactor $\left(0.1 \mathrm{dm}^{3}\right)$ connected to a vacuum line $\left(10^{-4} \mathrm{mbar}\right)$. The apparatus was heated, flushed with nitrogen, and degassed before the reaction was started. In the reactor equipped with a stirrer, $21 \mathrm{~cm}^{3}$ of THF and $2.7 \mathrm{~g} \mathrm{(21} \mathrm{mmol)} \mathrm{of} \mathrm{naphthalene} \mathrm{were}$ placed under nitrogen. When naphthalene was dissolved, $0.90 \mathrm{~g}(22 \mathrm{mmol})$ of potassium was added. After $30 \mathrm{~s}$ a green color characteristic of an anion-radical appeared. The reactor content was cooled and a temperature of 20 $25^{\circ} \mathrm{C}$ was maintained for $1 \mathrm{~h}$. The concentration of potassium naphthalene was checked

Table I. Characteristic data of the products of reactions of potassium naphthalene, Propylene oxide, $\mathrm{CO}_{2}$ (propylene carbonate), and $\alpha, \alpha^{\prime}$-dibromo-p-xylene ${ }^{\mathrm{a}}$

\begin{tabular}{|c|c|c|c|c|c|c|c|c|c|c|}
\hline \multirow{3}{*}{$\begin{array}{l}\text { Run } \\
\text { No. }\end{array}$} & \multirow{3}{*}{$\frac{\text { K-naphthalene }}{\mathrm{g}(\mathrm{mmol})}$} & \multirow{3}{*}{$\frac{\mathrm{PO}^{\mathrm{c}}}{\mathrm{g}(\mathrm{mmol})}$} & \multirow{3}{*}{$\frac{\mathrm{CO}_{2}}{\mathrm{~atm}}$} & \multirow{3}{*}{$\begin{array}{c}\begin{array}{c}\text { Propylene } \\
\text { carbonate }\end{array} \\
\mathrm{g}(\mathrm{mmol})\end{array}$} & \multirow{3}{*}{$\frac{\mathrm{DBX}^{\mathrm{d}}}{\mathrm{g}(\mathrm{mmol})}$} & \multicolumn{5}{|c|}{ Product } \\
\hline & & & & & & \multicolumn{3}{|c|}{$\begin{array}{l}\text { Elemental analysis } \\
\text { Found (Calcd) }\end{array}$} & \multirow{2}{*}{$\frac{\text { Yield }}{\%}$} & \multirow{2}{*}{$\frac{\eta_{\mathrm{sp}}^{\mathrm{b}}}{\mathrm{dl} \mathrm{g}^{-1}}$} \\
\hline & & & & & & $\% \mathrm{C}$ & $\% \mathrm{H}$ & $\% \mathrm{Br}$ & & \\
\hline 1 & $3.5(20)$ & $1.2(20)$ & 20 & - & $5.3(20)$ & $\begin{array}{r}67.4 \\
(67.4\end{array}$ & $\begin{array}{l}7.1 \\
7.6\end{array}$ & $\begin{array}{l}4.7 \\
4.5)^{\mathrm{e}}\end{array}$ & 74 & 0.10 \\
\hline 2 & $3.5(20)$ & $1.4(24)$ & 20 & - & $5.3(20)$ & & & & 70 & - \\
\hline 3 & $3.5(20)$ & $1.8(31)$ & 20 & - & $5.3(20)$ & & & & 58 & - \\
\hline 4 & $3.5(20)$ & - & - & $2.0(20)$ & $5.3(20)$ & $\begin{array}{r}70.4 \\
(71.6\end{array}$ & $\begin{array}{l}6.40 \\
6.4\end{array}$ & $\begin{array}{l}0.75 \\
-)\end{array}$ & 61 & 0.14 \\
\hline 5 & $3.5(20)$ & - & - & $2.4(24)$ & $5.3(20)$ & & & $0.7^{\prime}$ & 70 & 0.12 \\
\hline 6 & $3.5(20)$ & - & - & $2.6(26)$ & $5.5(20)$ & & & 1.0 & 63 & - \\
\hline
\end{tabular}

\footnotetext{
a For reaction conditions, see Exptl. Part.

b Specific viscosity of a $2 \%$ solution in $\mathrm{CHCl}_{3}$ at $25^{\circ} \mathrm{C}$.

c Propylene oxide.

d $\alpha, \alpha^{\prime}$-Dibromo- $p$-xylene.

e Calculated for polycondensation degree 7 .
} 
by titration with benzyl alcohol. Then $1.4 \mathrm{~g}$ $(24 \mathrm{mmol})$ of propylene oxide were introduced with intensive stirring and cooling of the reaction mixture. The green color turned to cherry-red. The reaction was carried out at $25^{\circ} \mathrm{C}$ for further $3 \mathrm{~h}$ until the red color turned to yellow. Gaseous carbon dioxide was passed through the reaction mixture and a white nonsedimented precipitate was formed.

The next step of reaction was carried out under carbon dioxide pressure in a $50 \mathrm{~cm}^{3}$ stainless steel autoclave. $5.3 \mathrm{~g}(20 \mathrm{mmol})$ of $\alpha, \alpha^{\prime}$-dibromo- $p$-xylene, $0.02 \mathrm{~g}(0.7 \mathrm{mmol})$ of 18-crown-6 ether and an appropriate amount of the reaction mixture (from the first step) containing $40 \mathrm{mmol}$ of alkyl-carbonate groups were placed in the autoclave. Gaseous carbon dioxide was introduced into the system under a pressure of $20 \mathrm{~atm}$ and the autoclave was heated at $80^{\circ} \mathrm{C}$. After completion of the reaction $(24 \mathrm{~h}), \mathrm{CO}_{2}$ was released from the autoclave and the solvent and naphthalene were distilled off. The residue was dissolved in $\mathrm{CHCl}_{3}$, and then $\mathrm{KBr}$ was filtered off and the

Table II. Characteristic data of products of the reactions of "living" polystyrene, ethylene carbonate, and dihalo compounds ${ }^{\mathrm{a}}$

\begin{tabular}{|c|c|c|c|c|c|c|c|c|c|c|c|}
\hline \multirow{3}{*}{$\begin{array}{l}\text { Run } \\
\text { No. }\end{array}$} & \multirow{3}{*}{$\frac{\mathrm{K}}{\mathrm{g}(\mathrm{mmol})}$} & \multirow{3}{*}{$\begin{array}{l}\begin{array}{c}\text { Naphtha- } \\
\text { lene }\end{array} \\
\mathrm{g} \text { (mmol) }\end{array}$} & \multirow{3}{*}{$\frac{\mathrm{St}}{\mathrm{g}(\mathrm{mmol})}$} & \multirow{3}{*}{$\begin{array}{c}\text { Ethylene } \\
\text { carbonate } \\
\mathrm{g}(\mathrm{mmol})\end{array}$} & \multirow{3}{*}{$\begin{array}{l}\text { Dibromo } \\
\text { compound } \\
\overline{\mathrm{g}(\mathrm{mmol})}\end{array}$} & \multirow{3}{*}{$\begin{array}{l}\text { Activating } \\
\text { agent } \\
\mathrm{g}(\mathrm{mmol})\end{array}$} & \multicolumn{5}{|c|}{ Product } \\
\hline & & & & & & & \multicolumn{3}{|c|}{$\begin{array}{l}\text { Elemental analysis } \\
\text { Found (Calcd) }\end{array}$} & \multirow{2}{*}{$\frac{\text { Yield }}{\mathrm{g}(\%)}$} & \multirow{2}{*}{$\frac{\eta_{\mathrm{sp}}^{\mathrm{b}}}{\mathrm{dl} \mathrm{g}^{-1}}$} \\
\hline & & & & & & & $\% \mathrm{C}$ & $\% \mathbf{H}$ & $\% \mathrm{Br}$ & & \\
\hline 1 & $0.41(10)$ & $1.23(9.5)$ & $14.02(130)$ & $0.55(6.3)$ & $\begin{array}{l}\mathrm{DBX}^{\mathrm{c}} \\
0.76(2.9)\end{array}$ & $\begin{array}{l}18-c-6 \\
0.02(0.7)\end{array}$ & $\begin{array}{r}88.9 \\
(90.5\end{array}$ & $\begin{array}{l}7.5 \\
7.6\end{array}$ & $\begin{array}{l}1.9 \\
-)\end{array}$ & $11.5(78)$ & 0.16 \\
\hline 2 & $1.31(34)$ & $3.96(36)$ & $16.51(160)$ & $1.16(13)$ & $\begin{array}{l}\text { DBX } \\
1.90(7.2)\end{array}$ & $\begin{array}{l}18-c-6 \\
0.03(1.1)\end{array}$ & & & & $8.5(50)$ & 0.13 \\
\hline 3 & $0.72(19)$ & $2.21(17)$ & $12.60(120)$ & $1.94(22)$ & $\begin{array}{l}\text { DBX } \\
2.97(11)\end{array}$ & $\begin{array}{l}18-c-6 \\
0.08(3.0)\end{array}$ & & & & $14.0(94)$ & 0.36 \\
\hline 4 & $1.10(28)$ & $3.36(26)$ & $8.90(90)$ & $2.33(26)$ & $\begin{array}{l}\text { DBX } \\
3.13(12)\end{array}$ & $\begin{array}{l}18-c-6 \\
0.09(3.4)\end{array}$ & & & & $11.1(96)$ & 0.11 \\
\hline 5 & $1.10(28)$ & $3.36(26)$ & $8.90(90)$ & $2.33(26)$ & $\begin{array}{l}\mathrm{DCX}^{\mathrm{d}} \\
2.07(12)\end{array}$ & $\begin{array}{l}18-c-6 \\
0.09(3.4)\end{array}$ & & & & $6.8(83)$ & 0.13 \\
\hline 6 & $1.10(28)$ & $3.36(26)$ & $8.90(90)$ & $2.33(26)$ & $\begin{array}{l}\mathrm{BDE}^{\mathrm{e}} \\
4.22(12)\end{array}$ & $\begin{array}{l}18-c-6 \\
0.09(3.4)\end{array}$ & & & & 9.7 (79) & 0.10 \\
\hline 7 & $1.10(28)$ & $3.36(26)$ & $8.90(90)$ & $2.33(26)$ & $\begin{array}{l}\mathrm{DBX} \\
3.13(12)\end{array}$ & $\begin{array}{l}\mathrm{PGL}^{\mathrm{f}} \\
0.1(3.5)\end{array}$ & & & 0.6 & $6.0(54)$ & 0.11 \\
\hline 8 & $1.10(28)$ & $3.36(26)$ & $8.90(90)$ & $2.33(26)$ & $\begin{array}{l}\text { DBX } \\
3.13(12)\end{array}$ & $\begin{array}{l}\text { TEBA } \\
0.07(3.5)\end{array}$ & & & 0.8 & $7.2(64)$ & 0.15 \\
\hline 9 & $1.10(28)$ & $3.36(26)$ & $8.90(90)$ & $2.33(26)$ & $\begin{array}{l}\text { DBX } \\
3.13(12)\end{array}$ & $\begin{array}{l}\text { BPPg } \\
0.14(3.4)\end{array}$ & & & 1.0 & $5.3(47)$ & 0.32 \\
\hline 10 & $1.10(28)$ & $3.36(26)$ & $8.90(90)$ & $2.33(26)$ & $\begin{array}{l}\text { DBX } \\
3.13(12)\end{array}$ & - & & & & $2.5(22)$ & 0.10 \\
\hline 11 & $1.10(28)$ & $3.36(26)$ & $8.90(90)$ & $2.33(26)$ & $\begin{array}{l}\text { DBX } \\
3.13(12)\end{array}$ & $\begin{array}{l}18-c-6 \\
0.09(3.4)\end{array}$ & & & & $6.8(61)$ & $0.13^{h}$ \\
\hline
\end{tabular}

a For reaction conditions, see Exptl. Part.

b The specific viscosity of a $2 \%$ solution in $\mathrm{CHCl}_{3}$ at $25^{\circ} \mathrm{C}$.

c $\alpha, \alpha^{\prime}$-Dibromo-p-xylene (DBX).

d $\alpha, \alpha^{\prime}$-Dichloro- $p$-xylene (DCX).

e $4,4^{\prime}$-Bis bromomethyl diphenyl ether (BDE).

f Polyglyme 300 (PGL).

g $n$-Butyltriphenyl phosphonium bromide (BPP).

h Reaction was carried out without $\mathrm{CO}_{2}$ pressure. 
organic layer was washed with water. The product was isolated from the solution by evaporating off the solvent in vacuo.

Synthesis of Polycarbonate from Potassium Naphthalene Propylene Carbonate and $\alpha, \alpha^{\prime}$ Dibromo-p-xylene. To a solution of potassium naphthalene (at $25^{\circ} \mathrm{C}$ ) an appropriate amount of propylene carbonate was added. The green color turned cherry-red and then after $3-4 \mathrm{~h}$ (at $50^{\circ} \mathrm{C}$ ) turned white-yellow. The reaction with $\alpha, \alpha^{\prime}$-dibromo- $p$-xylene was carried out in a stainless steel autoclave according to the procedure with propylene oxide. For more ditails see Table I.

Synthesis of a Polycarbonate Containing Polystyrene Blocks. To a solution of potassium naphthalene $\left(0.11-1.05 \mathrm{~mol}\right.$ in $\left.1 \mathrm{dm}^{3}\right)$ at $-60^{\circ} \mathrm{C}$ dry degassed styrene was introduced. The green color of the reaction mixture changed cherry-red. The reactor content was additionally stirred at room temperature for $30 \mathrm{~min}$, and an appropriate amount of ethylene carbonate in THF was added. The reaction was carried out for $1-2 \mathrm{~h}$ at $50^{\circ} \mathrm{C}$ and the cherry-red color turned yellow. The second step of the process was carried out in an autoclave with $\alpha, \omega$-dihalo compounds according to the method with propylene carbonate and potassium naphthalene.
The product was isolated by precipitation in methanol, then washed with water and dried i.vac. at room temperature. For more details, see Table II.

\section{Analytical Methods}

IR spectra were recorded on a Perkin-Elmer 521 spectrophotometer. ${ }^{1} \mathrm{H}-\mathrm{NMR}$ spectra were recorded on a $100 \mathrm{MHz}$ JEOL NMR spectrometer using TMS as an internal standard.

Elemental analysis was carried out on a Perkin-Elmer 240 apparatus. The intrinsic viscosity of the products was determined using an Ubbelohde viscometer at $25^{\circ} \mathrm{C}$ in $\mathrm{CHCl}_{3}$ as a solvent. Concentration of potassium naphthalene was determined by titration with benzyl alcohol.

\section{RESULTS AND DISCUSSION}

Polycarbonates from Potassium Naphthalene, Oxiranes, $\mathrm{CO}_{2}$, and $\alpha, \omega$-Dibromo Compound

The products obtained in the reaction of potassium naphthalene with propylene oxide, carbon dioxide and $\alpha, \alpha^{\prime}$-dibromo- $p$-xylene in THF in the presence of 18 -crown- 6 ether (eqs $1-3)$ were solids, soluble in polar solvents.

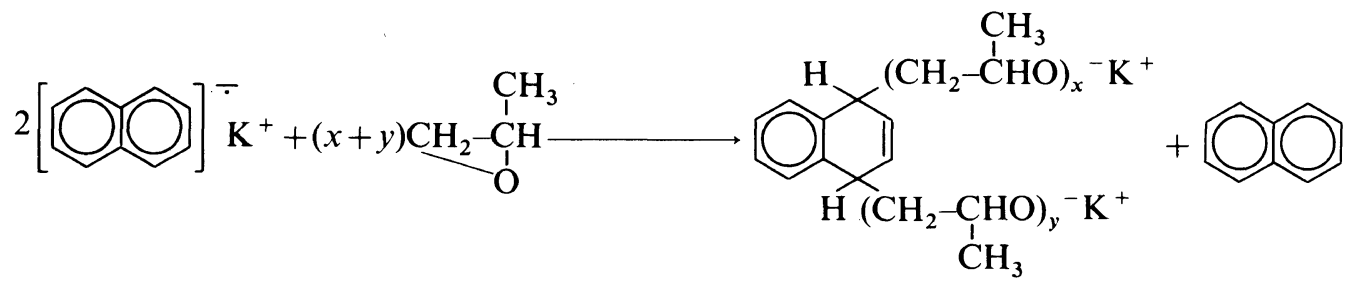

I<smiles>[Z7]C(=O)OC(=O)OC([3H])OC(C)CC1C=CC(C)c2ccccc21</smiles> 
$n \mathrm{II}+n \mathrm{BrCH}_{2} \mathrm{C}_{6} \mathrm{H}_{4} \mathrm{CH}_{2} \mathrm{Br} \stackrel{18-\mathrm{c}-6}{\longrightarrow}$

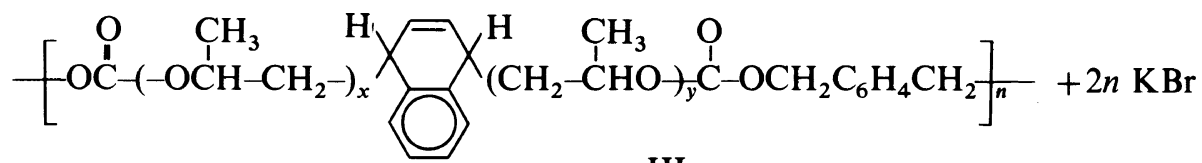

III

IR and ${ }^{1} \mathrm{H}$ NMR spectra of representative samples of the products obtained are shown in Figures $1 \mathrm{a}$ and $2 \mathrm{a}$. In the IR spectrum, strong absorption bands at 1735,1245 and $1125 \mathrm{~cm}^{-1}$ corresponding to the stretching vibration of carbonyl groups, $\mathrm{C}-\mathrm{O}$ bonds of linear carbonate and ether bonds, respectively, were observed. In the ${ }^{1} \mathrm{H}$ NMR spectrum, the following signals were present: aromatic protons in phenyl ring $(\delta=7.4 \mathrm{ppm})$ and dihydronaphthalene ring $(\delta=7.2 \mathrm{ppm})$, protons in unsaturated dihydronaphthalene $(\delta=5.8 \mathrm{ppm})$, benzyl methylene protons adjacent to carbonate bond $(\delta=5.2 \mathrm{ppm})$, methine proton adjacent to carbonate bond $(\delta=4.9 \mathrm{ppm})$, methylene protons adjacent to bromine atom $(\delta=$ $4.4 \mathrm{ppm})$, methylene and methine protons adjacent to ether bond $(\delta=3.6 \mathrm{ppm})$ and methyl protons $(\delta=1.3 \mathrm{ppm})$

The presence of the signals of methylene and methine protons $(\delta=3.6 \mathrm{ppm})$ in the ${ }^{1} \mathrm{H}$ NMR spectrum and absorption bands 1040 and $1125 \mathrm{~cm}^{-1}$ in the IR spectrum, however, indicate the incorporation of ether segments into the polymer chain under the conditions used.

It was found that a sufficient amount of carbon dioxide should be passed through the reaction mixture to transform all alcoholate anions into more thermodynamically stable alkyl-carbonate anions. When non-transformed alcoholate groups were present in the reaction system with $\alpha, \alpha^{\prime}$-dibromo- $p$ xylene, the product contained an insoluble yellow residue ( $p$-xylilidene fragments $\left.{ }^{10}\right)$.

\section{Polycarbonates from Potassium Naphthalene, \\ Cyclic Carbonates, and $\alpha, \omega$-Dibromo Com- pounds}

Literature reports on two pathways of nucleophilic attack onto the 1,3-dioxolan-2-one ring. Some nucleophiles (such as alcoholates, phenolates or thioalcoholates) attack the $\alpha$ carbon atom in the ring and $\beta$-hydroxy derivatives are formed, ${ }^{8}$ but the attack of nucleophiles such as aliphatic amines results in $\beta$-hydroxyurethane formation due to the ring opening at the carbonyl atom. ${ }^{11}$

To examine the mechanism of the reaction of anion-radicals and carbanions with cyclic carbonates, a model reaction of potassium naphthalene with propylene carbonate in THF was carried out.

The presence of terminal alkyl-carbonate anions resulting from the attack onto the $\alpha$ carbon atom of the 1,3-dioxolan-2-one ring (eq 4) was proved by the intensive evolution of $\mathrm{CO}_{2}$ when the post-reaction mixture was neutralized with hydrochloric acid.<smiles>[Y20][Te]c1ccc2ccccc2c1</smiles> 


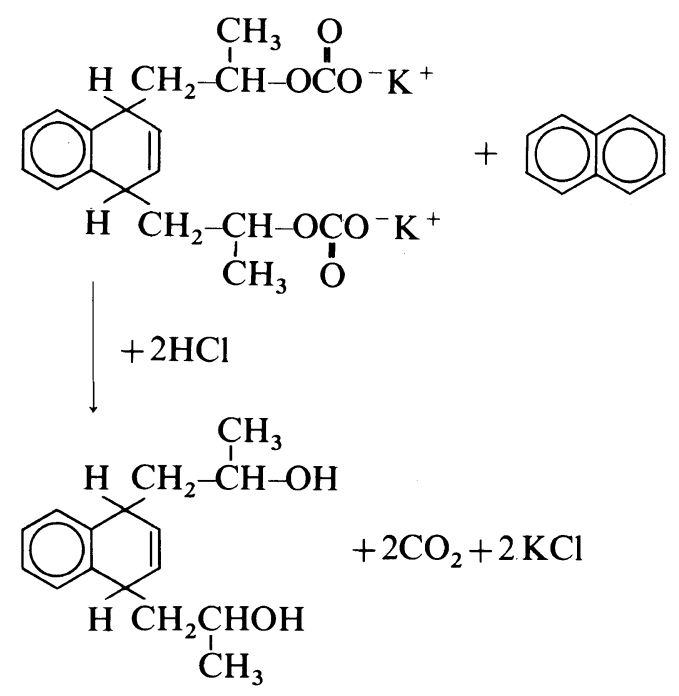

Furthermore, in the IR spectrum of the neutralized mixture, no absorption bands characteristic for stretching vibration of carbonyl groups, but only those corresponding to vibration of hydroxyl groups $\left(3500 \mathrm{~cm}^{-1}\right)$ were observed.

If the resulting product contained the ester linkages yielded from the attack on the carbonyl group (eq 5), carbon dioxide would have not appeared and in the IR spectrum, an absorption band $\left(1730-1740 \mathrm{~cm}^{-1}\right)$ characteristic for the carbonyl group of ester linkages should be present.

$$
2 \text { (2) }
$$


It was observed during the reaction of potassium naphthalene with propylene carbonate that in the first stage, the dark green color of the anion-radical turned cherry-red, character- istic of carbanions. Thus, the first step of the reaction is the addition of cyclic carbonate to the anion-radical (eq 6)<smiles>[Z4]COC(=O)OC(C)[CH]c1ccc2c(c1)C(CC(C)OC(=O)O[Y7])C=CC2</smiles>

Similarly, as in reactions of potassium naphthalene with oxiranes, ${ }^{5}$ the next step involves most probably a rapid exchange of an electron

with the initial radical-anion resulting in dianion $\mathrm{V}$ (eq 7).

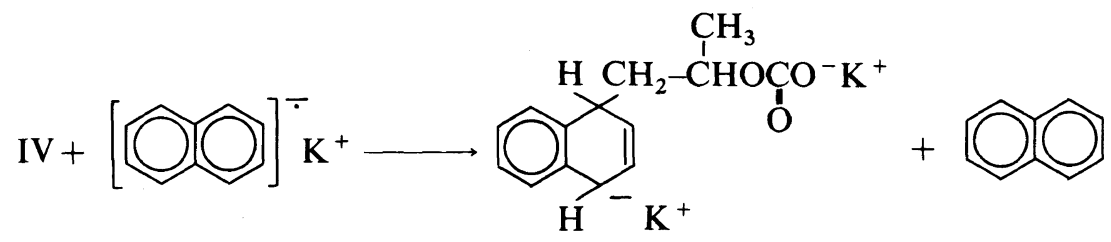

The carbanion $\mathrm{V}$ reacts with another molecule of cyclic carbonate to yield the (1,4- and 1,2-) dihydronaphthalene derivative with carbonate terminal groups (VI) (eq 8).

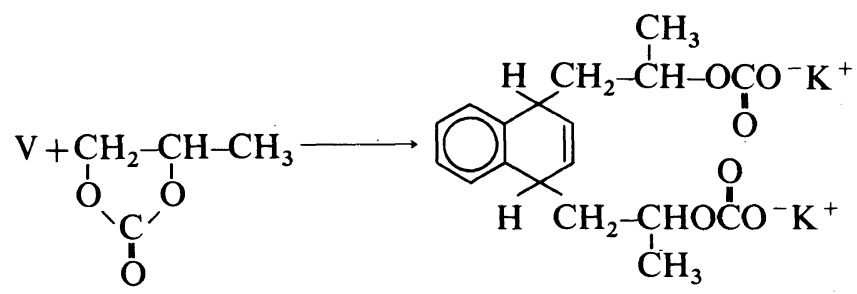

The reaction was accompanied by an exothermic effect, which was, however, lower than for the reaction with propylene oxide as a result of differences in the thermodynamic stability of different sized rings.

Since the reaction of potassium naphthalene with cyclic carbonate as was stated above, results in the product with alkyl-carbonate dianions, the synthesis of polycarbonate was performed, using the carbonate dianions in reactions with a $\alpha, \omega$-dibromo compound (eq 9). 

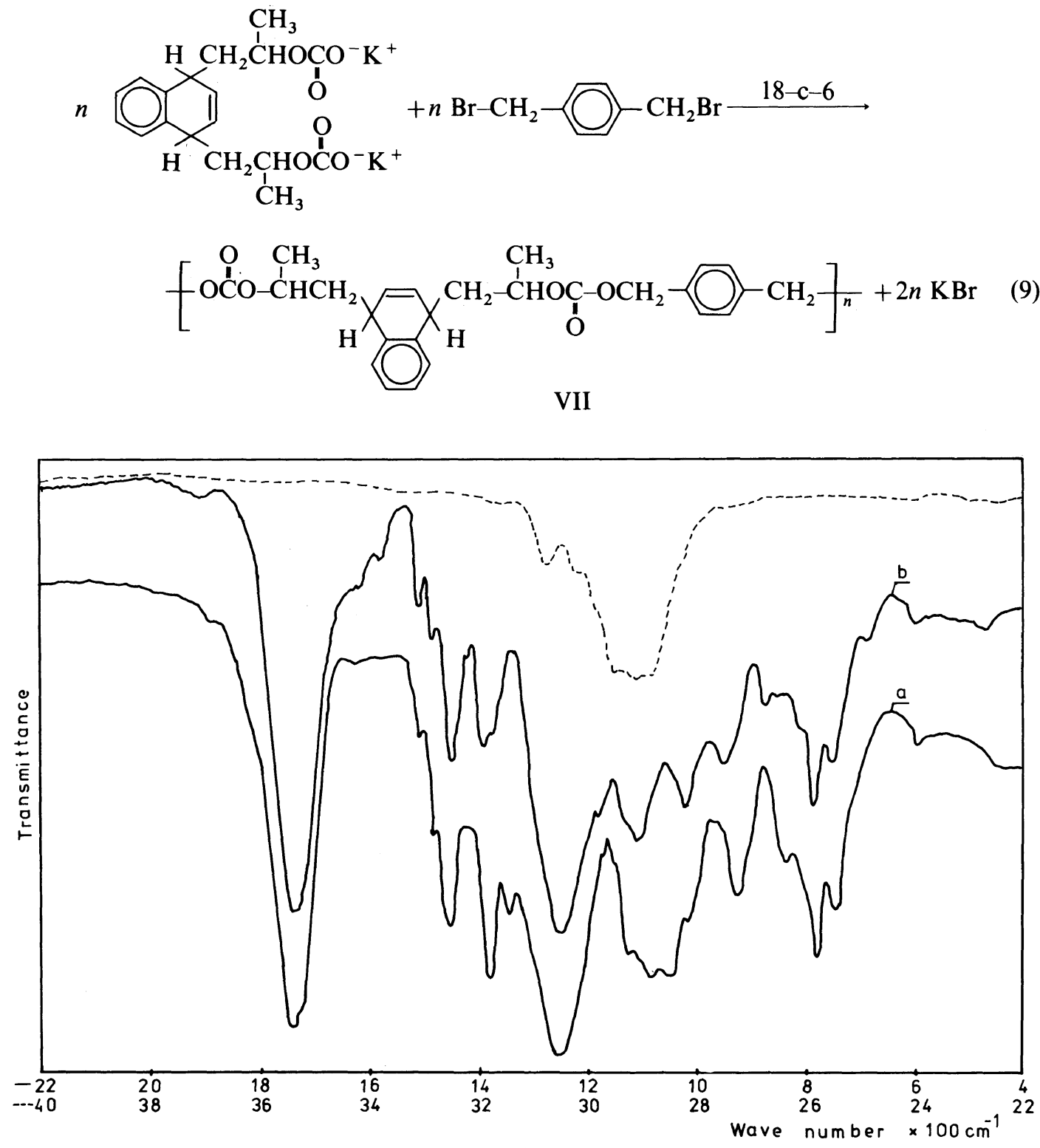

Figure 1. IR spectra of polycarbonates: a) from potassium naphthalene, propylene oxide, $\mathrm{CO}_{2}$, and $\alpha, \alpha^{\prime}$ dibromo-p-xylene; b) from potassium naphthalene, propylene carbonate, and $\alpha, \alpha^{\prime}$-dibromo- $p$-xylene.

The products of the reactions of potassium naphthalene, propylene carbonate and $\alpha, \alpha^{\prime}-$ dibromo- $p$-xylene in the presence of 18-crown6 ether (eqs 6-9) were solids soluble in polar organic solvents. The IR and ${ }^{1} \mathrm{H}$ NMR spectra of these polymers (Figures 1b, 2b) coincided with those of the products of the reaction where propylene oxide and $\mathrm{CO}_{2}$ were used instead of cyclic carbonate (III). The only difference was a lack of absorption bands at $1100-1200 \mathrm{~cm}^{-1}$ characteristic for ether linkages. In the ${ }^{1} \mathrm{H}$ NMR spectrum, the in- 


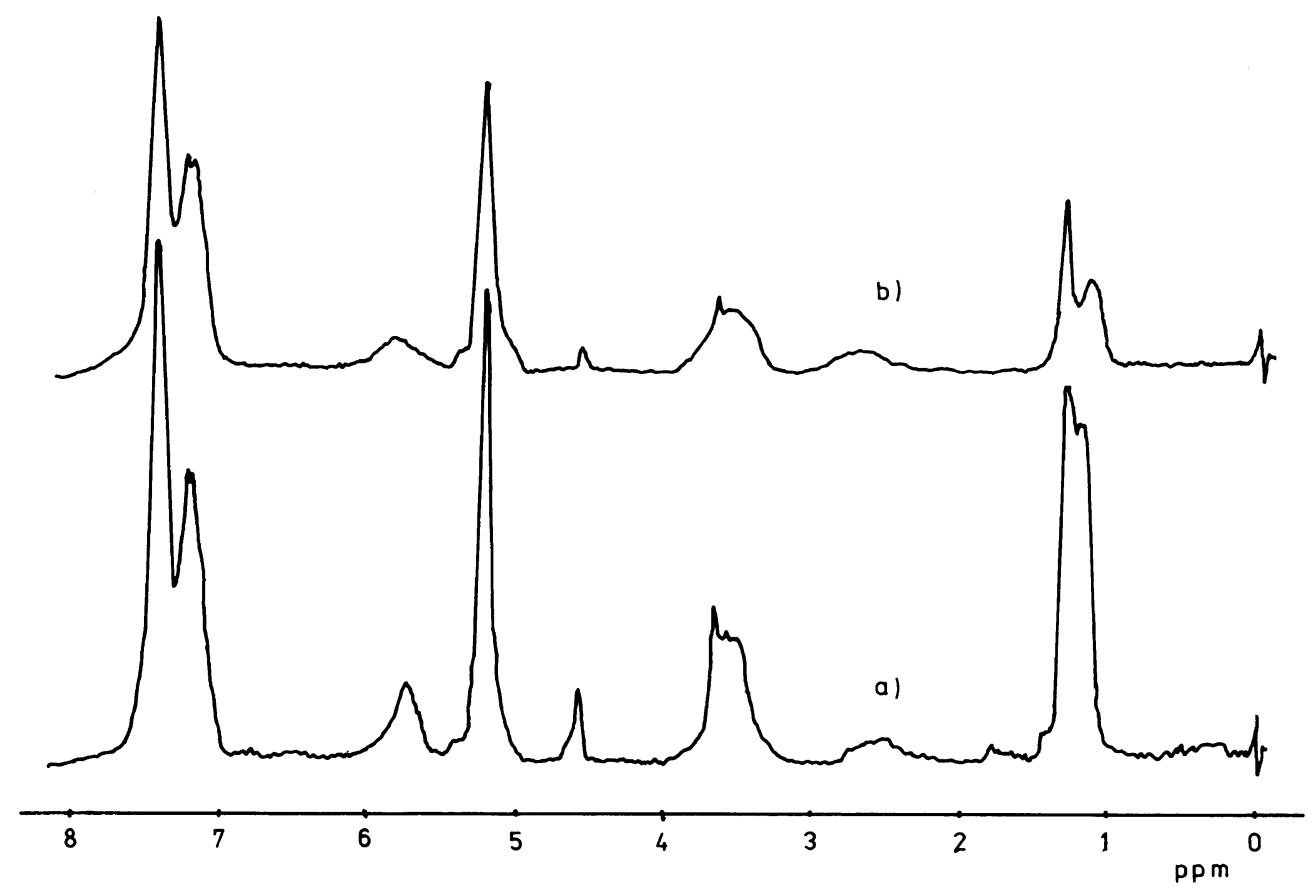

Figure 2. ${ }^{1} \mathrm{H}$ NMR spectra of polycarbonates: a) from potassium naphthalene, propylene oxide, $\mathrm{CO}_{2}$, and $\alpha, \alpha^{\prime}$-dibromo- $p$-xylene; b) from potassium naphthalene, propylene carbonate, and $\alpha, \alpha^{\prime}$-dibromo- $p$ xylene.

tensity ratio of the signals of methyl protons $(\delta=1.3 \mathrm{ppm})$ to dihydronaphthalene proton signals $(\delta=7.2 \mathrm{ppm})$ indicates the presence of only one propylene carbonate unit connected to the dihydronaphthalene ring from both sides in the replicable unit (VII). The 5membered ring of cyclic carbonate, in contrast to the 3-membered ring of oxirane, does not polymerize under such conditions. ${ }^{12,13}$

Yields and some characteristic data for products formed in reactions $6-9$ are given in Table I. The halogen content in these products indicates their rather low molecular weights $(n=15-18)$.

Polycarbonates with Polystyrene Blocks Obtained from "Living" Polystyrene, Ethylene Carbonate, and $\alpha, \omega$-dihalo Compounds

Considering the reaction of potassium naphthalene with cyclic carbonate where the 1,3dioxolan-2-one ring is subject to additive nu- cleophilic attack by the carbanion (eq 8), the reaction of "living" polystyrene containing two carbanion terminals with ethylene carbonate and $\alpha, \omega$-dihalo compounds in the presence of 18-crown-6 ether was carried out. A number of polymer syntheses were performed, where the molar ratio between styrene and potassium naphthalene was changed resulting in changes in the molecular weight of polystyrene chains.

The products, in the form of white precipitates, were found to contain linear carbonate linkages, indicating a process with opening of the 1,3-dioxolan-2-one ring at the methylene-oxygen bond. In the IR spectra (Figure 3) of the products, absorption bands at 1740,1600 and $1255 \mathrm{~cm}^{-1}$, corresponding to the stretching vibration of carbonyl groups, aromatic rings and $\mathrm{C}=\mathrm{O}$ groups were observed.

With increasing molecular weight of the 


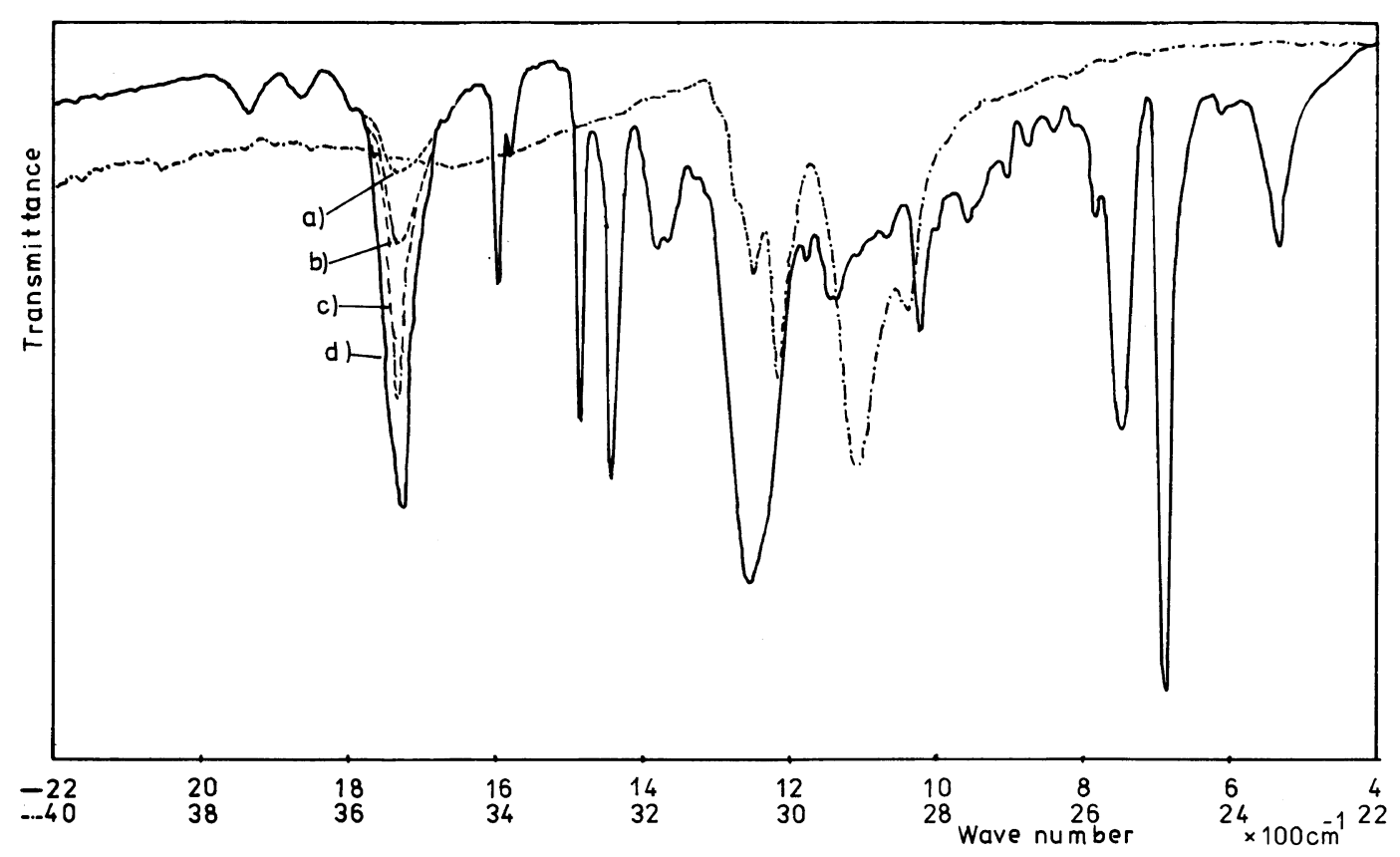

Figure 3. IR spectra of polycarbonates with polystyrene blocks: a) run No. 1; b) run No. 2; c) run No. 3 ; d) run No. 4 from Table II.

polystyrene blocks, the intensity of the absorp- On the basis of these results, the following tion band of the carbonyl group was decreas- reaction scheme can be considered a possible ing (using the absorption band at $1600 \mathrm{~cm}^{-1}$, reaction route to form polycarbonates with characteristic of polystyrene, as a reference). polystyrene blocks.

$$
\begin{aligned}
& 2[\bigcirc]^{-} \mathrm{K}^{+}+\underset{\substack{1 \\
\mathrm{Ph}}}{\mathrm{CH}}=\mathrm{CH}_{2} \longrightarrow
\end{aligned}
$$

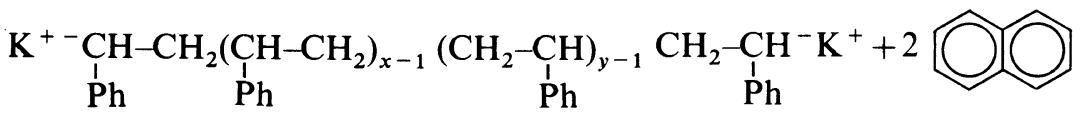

$$
\begin{aligned}
& \text { I }
\end{aligned}
$$

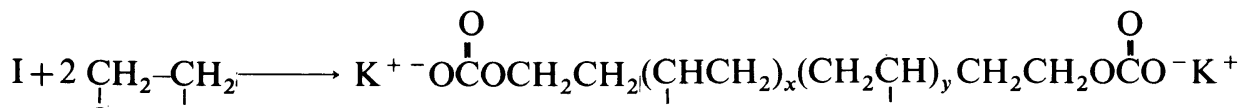

$$
\begin{aligned}
& \mathrm{O}_{\mathrm{C}^{\prime}} \mathrm{O} \\
& \mathrm{Ph} \\
& \mathrm{Ph}
\end{aligned}
$$

II 


$$
\begin{aligned}
& n \mathrm{II}+n \mathrm{Z}-\mathrm{R}-\mathrm{Z} \longrightarrow
\end{aligned}
$$

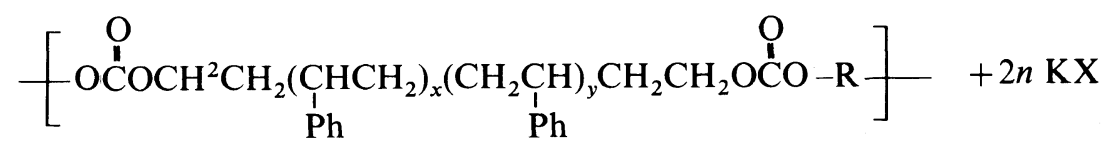

$$
\begin{aligned}
& \mathrm{R}=\mathrm{CH}_{2} \mathrm{PhCH}_{2}, \mathrm{CH}_{2} \mathrm{PhOPhCH}_{2} \\
& \mathrm{Z}=\mathrm{Cl}, \mathrm{Br} \\
& x=3-10 \quad y=3-10
\end{aligned}
$$

The results of experiments with various reagent ratios (potassium naphthalene/St) of products formed in reactions $10-12$ are given in Table II (run No. 1-4).

Also a number of syntheses of the above polymers was performed, using various halo compounds, anion activating agents and by changing the reaction conditions. As starting material, a "living" polystyrene of molecular weight about 600 was used. The results are shown in Table 2 (run No. 5-11). The use of the dichloro compound instead of the dibromo one resulted in lower yields and molecular weights. The dibromo compound structure was found to have no influence on the yield or molecular weights of the polymers obtained.

The possibility of obtaining polymers with using other than 18-c-6 anion activating agents was proved. However, the yields were lower, ranging between $45-65 \%$ (Table II, run No. 7-9).

When in the reaction with the dibromo compound no anion activating agent was used, a polymer containing carbonate bonds was also obtained but with very low yield $(20 \%)$ and low specific viscosity (Table II, run No. 10). It was shown that the reaction between polystyrene terminated with alkyl-carbonate anions and dibromo compound carried out without $\mathrm{CO}_{2}$ pressure led also to polycarbonates. This proves relative stability of alkylpotassium carbonates under the reaction conditions (temp, $80^{\circ} \mathrm{C}$ ) (Table II, run No. 11).

Condensation block-copolymer synthesis is a chemistry of end groups and its principal restriction is the availability of prepolymers possessing suitable reactive chain terminals. The present method based on reactions of carbanions with cyclic carbonates may be used for obtaining oligomers with alkyl-carbonate anions as terminal groups. Such capped oligomers create the possibility for obtaining various polymers which was shown in this paper from the example of condensation with $\alpha, \omega$-dihalo compounds.

Acknowledgement. This work was financially supported by the Polish Academy of Sciences.

\section{REFERENCES}

1. A. Rokicki and W. Kuran; J. Macromol. Sci.-Rev. Macromol. Chem., 21, 135 (1981).

2. C. J. Pedersen, J. Am. Chem. Soc., 89, 7017 (1967).

3. K. Soga, Y. Toshida, S. Hosoda, and S. Ikeda, Makromol. Chem., 178, 2747 (1977).

4. K. Soga, Y. Toshida, S. Hosoda, and S. Ikeda, Makromol. Chem., 179, 2379 (1978).

5. D. H. Richards and M. Szwarc, Trans. Faraday Soc., 55, 1644 (1959).

6. G. Fianz, Y. Gallot, J. Parrod, and P. Rempp, J. Polym. Sci., 58, 1363 (1962).

7. A. Polowińska and S. Połowiński, Makromol. Chem. Rapid Commun., 5, 399 (1984).

8. T. Yoshino, S. Inaba, and Y. Ishido, Bull. Chem. Soc. Jpn., 46, 553 (1973).

9. G. Rokicki, J. Pawlicki, and W. Kuran, Polym. J., 17, 509 (1985).

10. G. Rokicki, B. Pogorzelska-Marciniak, and W. Kuran, Polym. J., 14, 8 (1987).

11. M. F. El-Giamal and R. C. Schulz, Makromol. Chem., 177, 2259 (1976).

12. K. Soga, Y. Tazuke, S. Hosoda, and S. Ikeda, J. Polym. Sci., Polym. Chem. Ed., 15, 219 (1977).

13. W. Kuran and P. Górecki, Makromol. Chem., 184, 907 (1983). 